\title{
APPLICATION OF INTERACTIVE METHODS IN TEACHING COMPLEX ANALYSIS
}

\author{
Nurbol K. Abishev ${ }^{1}$, Bakhytkul Kaskatayeva ${ }^{2}$, \\ A.U. Dauletkulova ${ }^{3}$, Alma Bekbolganova ${ }^{4}$, Zauresh Toleukhanova ${ }^{5}$ \\ ${ }^{1}$ Department of Informatics and Informatization of Education \\ Kazakh National University named after Abai \\ Dostyk Ave. 13, Almaty, 050010, KAZAKHSTAN \\ 2,3,4,5 Department of Mathematics \\ Kazakh State Women's Teacher Training University \\ 99 Aiteke bi Street, Almaty, 050006, KAZAHSTAN
}

\begin{abstract}
The paper describes application of methods used upon teaching complex analysis. Currently teaching process in higher educational institutions requires permanent improvement, the drastic change of strategy and tactics of specialists' training. The conducted analysis of situation with training of future Maths teachers reveals insufficient use of interactive methods under conditions of teacher's educational facilities. The goal of this research is the development of such interactive methods for professionally-oriented training of future bachelors particularly, mathematicians - upon teaching complex analysis. The paper uses such research methods as theoretical analysis of problem, literature examination, observation, questioning and testing. As the result of study, students have demonstrated independence in using interactive methods during their educational practice. The work also includes variants of application of problem and heuristic methods for teaching complex analysis under conditions of different teaching process organization forms in teachers university.
\end{abstract}

AMS Subject Classification: 00A73, 97D50, 68Q10

Key Words: interactive model, problem and heuristic methods, university education

Received: $\quad$ May 29, 2017

Revised: $\quad$ July 2, 2017

Published: July 27, 2017

(C) 2017 Academic Publications, Ltd. url: www.acadpubl.eu

$\S_{\text {Correspondence author }}$ 


\section{Introduction}

At the present time teaching process requires continuous improvement, as far as there is a change of priorities and social values: the scientific and technical progress is increasingly considered a mean for achievement of such level, which satisfies to the maximum constantly growing demand of people and provides development of intellectual wealth of a person. Therefore, the current situation in specialists training should be fundamentally changed in terms of its strategy and tactics.

The tasks set by the President and the Government of the Republic of Kazakhstan to higher educational institutions imply specialists' professional training quality increase and achievement of world standards level. In such a way there is a necessity of training of competitive teachers possessing interactive teaching methods.

Development and implementation of such methods are represented in various areas of scientific knowledge and have been studied by many educationalists and psychologists. However, the conducted analysis of situation with future math teachers' training shows insufficient use of interactive methods in professionally-oriented teaching under conditions of teachers educational facilities. The present fact defines relevance of the work.

The goal of the research is the development of interactive methods for professionally-oriented training of future bachelors, particularly, mathematicians. The tasks are:

- to give classification of interactive forms and methods of professionallyoriented teaching;

- to develop application of problem method at laboratory lesson of complex variable theory;

- to apply heuristic method of professionally-oriented teaching when solving flow-related tasks.

One of the requirements to conditions of realization of basic educational programs for bachelors is the implementation and extensive use of active and interactive forms and methods of lessons' conducting within teaching process [1] and [2].

Depending on level of perceptual activity there can be several teaching models: passive, active and interactive.

In case of passive teaching a teacher serves as a source of knowledge being the central figure, while a student plays role of an educand (i.e. the passive listener, who have to be able to assimilate material and then reproduce it).

At the same time, active model considers students the educands, who enter 
dialogue with their teacher, actively participate in teaching process and perform creative, research and problem tasks. The model also implies definite selfdependence of students, individual execution of various tasks and solution of educational and research issues.

At last, one of the main directions of active teaching is the interactive training. The model is realized under conditions of constant active interaction between students, teacher and environment, and provides definite synergy in students actions. The student and the teacher in such a case are being equal teaching subjects. It should be also noted that in modern studies the term of interactivity is considered the interaction with computer and by means of computer as well.

The peculiarities of using active and interactive teaching methods are: dialogic interaction, feedback, working in small dynamic groups based on the principle of cooperation, active and role-based (playing) activity, problematics, students interaction between each other.

The interactive model provides significant change of role of teacher in educational process he no longer serves as a source of knowledge, but turns into helper and consultant, organizer and coordinator of lessons.

The conceptual part of education topic, as well as the form of knowledge delivery are changed either. When formulating goals of tasks solving, the emphasis is shifted from reinforcement of gained knowledge and skills to setting new goals and considering new problems [3].

Teaching of Maths also has its distinguishing features linked, above all, to the fact the content of the subject is understood to a greater degree via solution of tasks, demonstration of theoretical knowledge applying and interrelation between them in practice. So we tried to combine traditional and innovative means, forms and methods of teaching.

When studying advanced mathematics in teachers' college, we often use the following interactive methods of teaching: interactive lecture, brainstorming method, etc. [4].

In such a way, when choosing forms and methods of teaching, we took into account individual properties and abilities of students, activity of group, specific nature of definite course and content of educational material.

\section{Materials and Methods}

Speaking about the above mentioned variety of interactive forms and methods of teaching we often fall back on the form of "laboratory-based work" (when 
students under auspices of teacher and in accordance with preliminary shaped plan execute definite practical tasks). Such an approach is usually considered a problem method. Students take some task, for example, "to give geometric interpretation for operation with complex numbers". This task implies involvement of heuristic activity by students.

Teacher: "In such a way, for complex numbers there are several representations: matrix, algebraic, trigonometric and conformal. It has been revealed the matrix representation proves existence of complex numbers. Your task is to prove the algebraic representation is evident when it comes to geometric interpretation for operation of complex numbers' addition [5]. The exponential representation can be useful when multiplying and calculating root of some degree in case of complex number. At the same time the most effective way of expressing Moivre formula is the trigonometric representation".

Afterwards, students placed to a new situation seek for ways of set problem's solution they had never used before and, thus, being unknown to them.

Geometric interpretation for addition.

Addition of complex numbers is performed with triangle rule, as shown by vectors in Figure 1. For operations of addition it is better to use algebraic expression:

$$
z_{1}+z_{2}=z \Leftrightarrow\left\{\operatorname{Re} z_{1}+\operatorname{Re} z_{2}=\operatorname{Re} z, \operatorname{Im} z_{1}+\operatorname{Im} z_{2}=\operatorname{Im} z\right\} .
$$

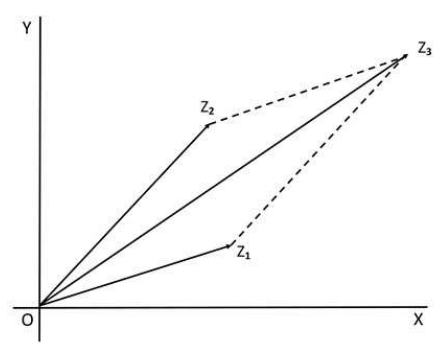

Figure 1: Geometric interpretation for addition

Multiplication is better to perform using exponential form of complex numbers' expression.

$$
\begin{gathered}
z_{1} z_{2}=\left|z_{1}\right|\left|z_{2}\right| \operatorname{epx}\left(i\left(\arg z_{1}+\arg z_{2}\right)\right) \Leftrightarrow\left|z_{1} z_{2}\right|=\left|z_{1}\right|\left|z_{2}\right|, \\
\arg \left(z_{1} z_{2}\right)=\arg z_{1}+\arg z_{2} .
\end{gathered}
$$

In geometrical terms the addition of arguments of complex numbers means counterclockwise rotation of number with bigger argument to angle being equal to smaller argument. In the figure below $z_{2}$ is directed to angle $\phi_{2}$, since $\phi_{2}>\phi_{1}$ (Fig. 2). 


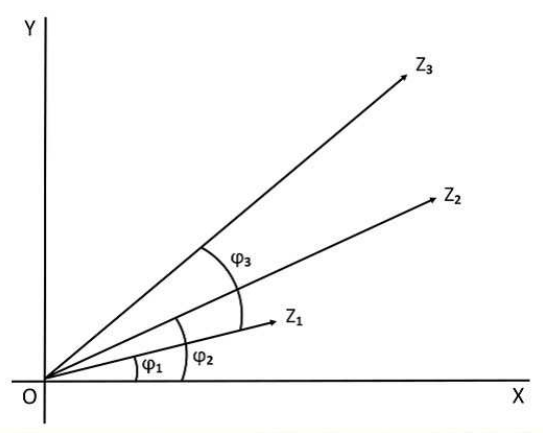

Figure 2: Geometric interpretation for multiplication

Exercise. Give geometric interpretation for dividing.

Geometric representation of natural degree roots of complex numbers.

As far as $\sqrt[n]{z} \sqrt[n]{z} \ldots \sqrt[n]{z}=z$, the $\arg z=\arg \sqrt[n]{z}+\arg \sqrt[n]{z}+\ldots+\arg \sqrt[n]{z}$ or $\arg \sqrt[n]{z}=\frac{\operatorname{argz}}{n}$. Consequently, to calculate argument of one of roots the argument $z$ should be divided by $n$. On the other hand,

$$
\begin{aligned}
& \sqrt[n]{z}=\sqrt[n]{|z| \exp (i \operatorname{iarg} z+2 \pi k i)}=\sqrt[\mathrm{n}]{|z|} \exp \left(\frac{\operatorname{iarg} z+2 \pi k i}{n}\right)= \\
&=\sqrt[n]{|z|} \exp \left(\frac{\operatorname{iarg} z}{n}\right) \exp \left(\frac{2 k \pi i}{n}\right)=z_{1} \exp \left(\frac{2 k \pi i}{n}\right)
\end{aligned}
$$

where $z_{1}$ is the first root. It follows herefrom the subsequent roots differ from the first one only with argument value. In other words, all the subsequent roots are taken by rotation of the first root to angle $\frac{2 \pi}{n} k$. The number of such rotation in the plane can make only $n$. Thus, all the roots (the number of which is $n$ ) lay within single circle and divide the circle into equal arcs. In figure 2 there are quartic roots of unit imaginary number.

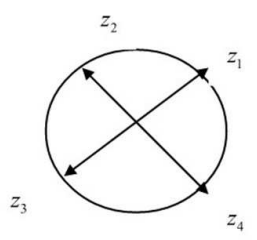

Figure 3: Geometric interpretation of dividing

The algorithm for calculating $n$ degree roots of a complex number.

- number's argument is divided by $n$, while in the plane we draw a line corresponding to obtained angle; 
- in the line we mark the length that is equal to root of initial number module;

- then we draw circle crossing the marked point with center in origin of coordinates;

- finally, we divide the circle by $n$ of equal parts in the way one of the dividing points matches the point marked in the line.

\section{Results and Discussion}

When solving a problem concerning rationality of this or that method, we use heuristic method for solution of tasks of applying famous theorem of Zhukovsky N.E. (the Joukowski theorem).

Heuristics is the science dealing with patterns for development of new actions in non-standard, new situation, i.e. - the organization of efficient intellectual processes, on the basis of which intensification of ideas (hypotheses) generation process and consequential increase of their reasonableness (probability, certainty) are performed. Besides, heuristics represents an aggregate of man's cogitative mechanisms that provide procedures aimed at solution of creative tasks [6] and [7].

As a science, heuristics performs the following tasks:

- learning of common factors of intellectual processes on the basis of psychological features of their execution;

- selection and description of real situations that involve heuristical activity of man or its elements;

- studying of principles of organization of conditions for heuristical activity;

- modeling of situations, in which man exhibits heuristical activity for the purpose of studying its execution and how to organize it;

- creation of goal-oriented heuristical systems (the general and the particular) on the basis of perceived objective laws of heuristical activity;

- designing of technical devices that actualize laws of heuristical activity.

Thus, the main task of heuristics as cross-disciplinary scientific branch is the studying of patterns for development of new actions in new situation. The new situation is considered an unsolved task or uninvented technical device, the necessity of which has been revealed. In the pedagogics of professionallyoriented teaching new is, among others, the situation when an educand faces some non-standard task being out of his level of training. Facing a new situation any man seeks for ways of its resolving, the ways he had never used in practice before. If a situation cannot be called "new", man's actions, as a rule, bear 
algorythmical nature, i.e. he just recalls their sequence, which will obligatory lead him to solution. Such actions contain no elements of heuristic thinking as opposed to a new situation, when result should be new in objective or subjective terms. The objectively new result is that taken for the first time ever. The subjectively new result is that being new for a man, who has obtained it. The famous theorem of Zhukovsky N.E. (1904) states: the lifting force affecting a streamline in its intensity equals to multiplication of circulation, density and rate of speed values at infinity with direction pertaining the right angle towards circulation (at $G>0$ - clockwise, at $G<0$ - counterclockwise) [2].

When examining above mentioned and following issues students are suggested to prepare and present a report about deserts of Zhukovsky N.E. in complex variable theory and solve tasks using heuristic method.

Let's consider tasks of flowing a flat plate.

Broken down, such a flat plate represents a rectilineal interval of 2 a long. With help of Zhukovsky's function the interval can be inserted to circle with radius 1 (fig. 4), in such a case its exterior will be the circles exterior.
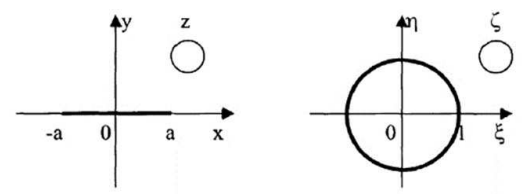

Figure 4: The interval inserted to circle with radius 1.

Thus, the complex potential for the flow of plate located at angle of attack to oncoming flow (fig. 5) will make:

$$
w=U z-i V \sqrt{z^{2}-a^{2}}
$$

where $U$ and $V$ are the projections of speed vector at $X-Y$ axis.

Circulation $G=-2 \pi a\left|v_{\infty}\right| \sin a$.

The force affecting the plate is perpendicular to $v_{\infty}$,

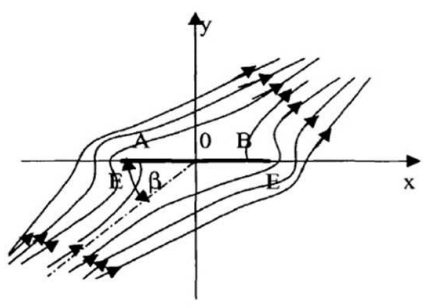

Figure 5: The complex potential for the flow of plate. 
The point of force application is located at a distance of its length from plate's front edge.

\section{Conclusion}

Using interactive methods in the learning process allows students to acquire the missing knowledge from different sources; use the acquired knowledge to solve practical problems; acquire communication skills, develop research skills.

\section{References}

[1] E.B. Aleksandrova, E.A. Sventsitskaya, Complex variable theory, SPb, publishing office of Herzen University (2006).

[2] A.I. Markulevich, Complex numbers and conformal maps, Moscow (1960).

[3] G.I. Sarantsev, If we need interactive forms of teaching? Problems of modern mathematical education in higher educational institutions and schools of Russia: the interactive forms of students and pupils' teaching. Materials of 5th All-Russian scientificmethodological conference, Kirov: publishing office of VyatGGU (2012), 42-48.

[4] S.B. Stupina, Technologies of interactive teaching in higher school, Saratov, publishing center "Nauka" (2009).

[5] M.I. Shabunin, Y.V. Sidorov, Complex variable theory, Moscow (2016). http://fictionbook.ru/author/m_i_shabunin /teoriya_funkciyi_kompleksnogo_peremennogo/

[6] V.N. Sokolov, Pedagogical heuristics, Moscow, Aspekt-Press (1995).

[7] S.A. Makushkin, Evaluation system of quality of electronic educational publications and resources used in educational process organization, Materials of the Afanasiev Readings, Vol. 1, No. 14 (2016), 209-214. 